\title{
TEXTURE DEVELOPMENT IN FERRITIC STAINLESS STEEL SHEET
}

\author{
M. YANTAÇ, W. T. ROBERTS and D. V. WILSON \\ Department of Industrial Metallurgy \\ University of Birmingham, England
}

(Received November 17, 1971)

\begin{abstract}
Two grades of ferritic stainless steels ( 405 and 410 .types) containing about $13 \%$ chromium have been processed by cold rolling with intermediate and final anneals. The development of textures has been followed and the plastic anisotropy of the annealed sheet has been assessed. Processing conditions for the development of anisotropy favourable for deep drawing applications have been defined for the 405 type stainless steel. The evolution of the favourable $\{554\}\langle 225\rangle$ texture component appears to be progressive throughout the processing. It is particularly well-developed after two moderate cold rolling reductions of about $70 \%$ and a final anneal at $850-900^{\circ} \mathrm{C}$. Differences between the 405 and 410 steels have been attributed to differences present in the early stages of processing.
\end{abstract}

\section{INTRODUCTION}

There is an extensive body of published work relating to texture development in low carbon rimmed and killed steel strip ${ }^{\text {e.g. }}{ }^{-6}$, much of which is concerned with the production of recrystallisation textures associated with anisotropic characteristics favourable for deep drawing.

In ferritic stainless steels, the phenomenon of ridging has stimulated some interest in texture development ${ }^{7,8}$, but, with the exception of work by Gokyu and Suzuki ${ }^{9}$ on steels containing $18 \%$ chromium, there is an absence of information in the open literature on the promotion of textures favourable for deep drawing in ferritic stainless steels.

Such information would be useful in the development of applications of ferritic stainless steels in the manufacture of press-formed components for service under corrosive conditions which do not call for the more expensive austenitic stainless steels.

Because of the similarity in crystal structure between ferritic stainless steels and deep drawing quality low carbon steels, it seemed likely that some guidance to the behaviour of ferritic steels under a range of processing conditions might be obtained from knowledge of the behaviour of low carbon steels. However, an important difference in the processing routes of the two classes of materials arises from the fact that whereas the low carbon steels are usually cold rolled from the hot band with a single cold rolling reduction, it is generally necessary to introduce an intermediate anneal in the cold rolling of the ferritic stainless steels.

In the present work the development of textures and mechanical anisotropy at various stages in the rolling and annealing of ferritic stainless steels containing about $13 \%$ chromium has been followed.

\section{EXPERIMENTAL PROCEDURE}

The compositions of the two steels used in this investigation are shown in Table 1 . Most of the results refer to the steel containing a small addition of aluminium, referred to as 405 steel. Both steels were received in the hot rolled and softened condition at a thickness of about $6.25 \mathrm{~mm}$ ( $0.25 \mathrm{in})$. They had been hot rolled under nominally similar conditions, but, after hot rolling, the 405 steel was softened at $750^{\circ} \mathrm{C}$ for 2 hours whereas the 410 steel was given a post hot-rolling heat treatment of $900^{\circ} \mathrm{C}$ for $10 \mathrm{~min}$ followed by $800^{\circ} \mathrm{C}$ for 2 hours. Differences in the as-received condition are thought to account for some of the differences in subsequent behaviour of the two materials.

The 405 steel was cold rolled with first reductions varying between 0 and $82 \%$, intermediate annealing temperatures in the range $750-1050^{\circ} \mathrm{C}$, second cold reductions between 87.5 and $30 \%$ and final annealing temperatures from $750-1100^{\circ} \mathrm{C}$. Final 
TABLE I

\begin{tabular}{lcccccccc}
\hline B.S. Specification & $\mathrm{C}$ & $\mathrm{Si}$ & $\mathrm{Mn}$ & $\mathrm{S}$ & $\mathrm{P}$ & $\mathrm{Cr}$ & $\mathrm{Ni}$ & $\mathrm{Al}$ \\
\hline 405. S17 (405 type) & 0.06 & 0.48 & 0.40 & 0.005 & 0.021 & 12.60 & 0.45 & 0.15 \\
410. S21 (410 type) & 0.05 & 0.12 & 0.40 & 0.013 & 0.022 & 13.25 & 0.30 & - \\
\hline
\end{tabular}

thickness of the sheet was fixed at $0.63 \mathrm{~mm}$ (0.025 in). The effect of a particular variable was evaluated from a series of experiments in which other variables were kept constant.

Cold rolling was carried out with paraffin lubrication and the same end of the strip was introduced into the rolls in each pass. Generally, annealing was carried out in a vacuum furnace with a heating rate in the range $500-700^{\circ} \mathrm{C}$ of $3.3^{\circ} \mathrm{C} / \mathrm{min}$. The cooling procedure after annealing at temperatures above $800^{\circ} \mathrm{C}$ involved holding at $750^{\circ} \mathrm{C}$ for 1 hour.

Standard procedures were used for mechanical testing involving $R$ value measurements, $\bar{R}$ being defined as

$$
\bar{R}=\frac{R_{0}+R_{90}+2 R_{45}}{4}
$$

and planar anisotropy being assessed by $\Delta R$, where

$$
\Delta R=\frac{R_{0}+R_{90}}{2}-R_{45}
$$

Deep drawing tests were made on a Hille deep drawing press, with a flat-bottomed punch diameter $50 \mathrm{~mm}$, profile radius $5 \mathrm{~mm}$, and a die of diameter $52.6 \mathrm{~mm}$ and profile radius $9.1 \mathrm{~mm}$. A single-blank draw-fracture test ${ }^{10}$ was used to determine the limiting drawing ratio, and for comparison in a few instances a full Swift deep drawing test was made.

A Siemens texture goniometer was used for the $\{200\}$ pole figures, and inverse pole figure results are expressed in terms of $f_{h k l}{ }^{11}$, defined as

$$
f_{h k l}=\frac{N_{h k l}\left(I_{h k l} / I_{R, h k l}\right)}{\sum N_{h k l}\left(I_{h k l} / I_{R, h k l}\right)}
$$

where $I_{h k l}$ is the intensity of the $h k l$ reflection from the sheet surface.

$I_{R, h k l}$ is the intensity of the same reflection from a random sample

and $\quad N_{h k l}$ is the multiplicity factor.

\section{RESULTS}

A list of the treatments is given in Tables 2 and 3. $R$ values at $0^{\circ}, 45^{\circ}$ and $90^{\circ}$ to the rolling direction and inverse pole figure data were obtained for these treatments, with a few exceptions, and selected $\{200\}$ pole figures were plotted.

A sequence of texture development in the 405 steel (Treatment 3 ) from the starting condition to the final annealed condition is shown in Figure 1.

For the 405 steel, the effects of variations in the second cold reduction, the intermediate annealing temperature and the final annealing temperature are shown in Figures 2-6. In all these figures, only five of the eight reflections measured for inverse pole figure data are plotted, in order to avoid confusion in the diagrams. Of the orientations not shown, 110 was generally at a very low level, less than $1 \%$. The remaining two orientations, 310 and 210 , were both minor components and did not show any definite trends.

From these results it was possible to narrow down the range of the processing variables to obtain the highest level of $\bar{R}$, and treatments 23-29 explored these ranges in more detail. With all these treatments, high levels of $\bar{R}(>1.7)$ were obtained, the maximum value of $\bar{R}$ being obtained following treatment $24(\bar{R}=2.00)$. It was anticipated that treatment 29 would lead to an even higher value, but an error in the cooling cycle which meant that the samples were not held at $750^{\circ} \mathrm{C}$ may have contributed to the slightly lower value of $\bar{R}=1.82$.

The enhancement of the $\{554\}\langle 225\rangle$ component when the final annealing temperature was raised from $750^{\circ} \mathrm{C}$ to $900^{\circ} \mathrm{C}$ is shown by comparing Figure 1d with Figure 7.

Heavy second cold reductions lead to a welldefined recrystallisation texture with $\{554\}\langle 225\rangle$ prominent, together with a strong $\{100\}\langle 011\rangle$ component (Figure 8), resulting in very low levels of $\bar{R}$.

When the 410 steel was compared with 405 steel following similar processing routes (treatments 40-42, Table 3 compared with 24-26, Table 2), it was apparent that the level of $\bar{R}$ values in the former steel was considerably lower than in the 405 . The corresponding differences in texture are represented in Table 4.

Texture development in the 410 steel (treatment 42) is shown in Figure 9. Comparison of Figure 9a 
TABLE II

Processing history and $R$ values of 405 type steel

\begin{tabular}{|c|c|c|c|c|c|c|c|c|c|c|}
\hline $\begin{array}{l}\text { Treatment } \\
\text { number }\end{array}$ & $\begin{array}{l}\text { Treatment prior } \\
\text { to cold rolling }\end{array}$ & $\begin{array}{l}\text { First } \\
\text { cold } \\
\text { reduction } \\
(\%)\end{array}$ & $\begin{array}{l}\text { Intermediate } \\
\text { annealing } \\
\text { temperature } \\
\left({ }^{\circ} \mathrm{C}\right) \\
(\text { time }=1 \mathrm{hr})\end{array}$ & $\begin{array}{l}\text { Second } \\
\text { cold } \\
\text { reduction } \\
(\%)\end{array}$ & $\begin{array}{c}\text { Final } \\
\text { annealing } \\
\text { temperature } \\
\left({ }^{\circ} \mathrm{C}\right) \\
(\text { time }=1 \mathrm{hr})\end{array}$ & $R_{0}$ & $R_{45}$ & $R_{90}$ & $R$ & $\Delta R$ \\
\hline 1 & - & 0 & - & 87.5 & 750 & 0.51 & 1.32 & 0.70 & 0.96 & -0.71 \\
\hline 2 & - & 0 & - & 87.5 & 1050 & 0.46 & 1.29 & 0.64 & 0.92 & -0.74 \\
\hline 3 & - & 58 & 750 & 70 & 750 & 1.38 & 1.39 & 1.88 & 1.51 & +0.24 \\
\hline 4 & - & 58 & 1050 & 70 & 750 & 1.33 & 1.01 & 1.92 & 1.32 & +0.62 \\
\hline 5 & - & 58 & 750 & 70 & 1050 & 1.40 & 1.47 & 1.88 & 1.56 & +0.17 \\
\hline 6 & - & 58 & 1050 & 70 & 1050 & 1.35 & 1.16 & 1.72 & 1.35 & +0.38 \\
\hline 7 & - & 65 & 750 & 65 & 750 & 1.64 & 1.52 & 2.22 & 1.72 & +0.41 \\
\hline 8 & - & 69 & 750 & 60 & 750 & 1.43 & 1.36 & 1.97 & 1.53 & +0.34 \\
\hline 9 & - & 69 & 750 & 60 & 1050 & 1.22 & 1.35 & 1.87 & 1.45 & +0.20 \\
\hline 10 & - & 82 & 750 & 30 & 750 & 0.83 & 1.61 & 1.34 & 1.34 & -0.53 \\
\hline 11 & - & 82 & 1050 & 30 & 750 & 0.73 & 1.46 & 1.10 & 1.19 & -0.55 \\
\hline 12 & - & 82 & 750 & 30 & 1050 & 0.79 & 1.35 & 1.07 & 1.13 & -0.42 \\
\hline 13 & - & 82 & 1050 & 30 & 1050 & 0.73 & 1.28 & 1.04 & 1.08 & -0.40 \\
\hline 14 & -. & 58 & 750 & 70 & 820 & 1.69 & 1.60 & 2.34 & 1.81 & +0.42 \\
\hline 15 & - & 58 & 750 & 70 & 860 & 1.81 & 1.78 & 2.44 & 1.95 & +0.35 \\
\hline 16 & - & 58 & 750 & 70 & 900 & 1.87 & 1.66 & 2.38 & 1.89 & $\begin{array}{l}0.47 \\
\end{array}$ \\
\hline 17 & - & 58 & 750 & 70 & 1000 & 1.53 & 1.58 & 2.12 & 1.70 & $\begin{array}{r}0.25 \\
+\end{array}$ \\
\hline 18 & - & 58 & 750 & 70 & 1100 & 1.44 & 1.48 & 1.87 & 1.57 & +0.18 \\
\hline 19 & - & 58 & 1050 & 70 & 820 & 1.65 & 1.23 & 2.35 & 1.62 & $\begin{array}{r}0.77 \\
+0.10\end{array}$ \\
\hline 20 & - & 58 & 1050 & 70 & 900 & 1.89 & 1.39 & 2.35 & 1.75 & $\begin{array}{r}0.73 \\
\end{array}$ \\
\hline 21 & - & 58 & 1050 & 70 & 1000 & 1.52 & 1.36 & 2.07 & 1.58 & +0.44 \\
\hline 22 & - & 58 & 1050 & 70 & 1100 & 1.48 & 1.21 & 1.87 & 1.44 & +0.46 \\
\hline 23 & - & 58 & 750 & 70 & $820^{c}$ & 1.84 & 1.75 & 2.50 & 1.96 & $\begin{array}{r}0.40 \\
+0.42\end{array}$ \\
\hline 24 & - & 58 & $820^{a}$ & 70 & $820^{c}$ & 1.80 & 1.87 & 2.44 & 2.00 & $\begin{array}{r}1.42 \\
+0.25\end{array}$ \\
\hline 25 & - & 58 & 820 & 70 & 820 & 1.91 & 1.65 & 2.47 & 1.92 & +0.54 \\
\hline 26 & - & 58 & 820 & 70 & 900 & 1.51 & 1.45 & 2.04 & 1.67 & +0.33 \\
\hline 27 & - & 58 & $950^{\mathrm{b}}$ & 70 & 820 & 1.70 & 1.51 & 2.20 & 1.73 & +0.44 \\
\hline 28 & - & 58 & 750 & 70 & 860 & 1.81 & 1.78 & 2.44 & 1.95 & $\begin{array}{r}1.34 \\
+0.35\end{array}$ \\
\hline 29 & - & 65 & 820 & 65 & $860^{c d}$ & 1.70 & 1.67 & 2.25 & 1.82 & +0.31 \\
\hline 30 & - & - & - & - & - & & & & & \\
\hline 31 & $\begin{array}{l}\text { Heated to } 1000^{\circ} \mathrm{C} \\
\text { Air cooled }\end{array}$ & - & - & - & - & & & & & \\
\hline 32 & $\begin{array}{l}\text { Heated to } 1000^{\circ} \mathrm{C} \\
\text { Air cooled }\end{array}$ & 58 & 820 & 65 & 860 & 1.45 & 1.62 & 2.34 & 1.76 & +0.28 \\
\hline 33 & $\begin{array}{l}\text { Heated to } 1000^{\circ} \mathrm{C} \\
\text { Air cooled }\end{array}$ & 58 & 860 & - & - & 0.52 & 0.82 & 1.08 & 0.81 & -0.02 \\
\hline 34 & $\begin{array}{l}\text { Hot rolled } 62 \% \text { at } \\
850^{\circ} \mathrm{C} \\
\text { Annealed } 800^{\circ} \mathrm{C}\end{array}$ & 60 & 860 & - & - & 1.01 & 1.37 & 1.52 & 1.32 & -0.11 \\
\hline 35 & $\begin{array}{l}\text { Hot rolled } 62 \% \text { at } \\
850^{\circ} \mathrm{C} \\
\text { Annealed } 800^{\circ} \mathrm{C}\end{array}$ & 80 & 860 & - & - & 0.91 & 1.34 & 1.40 & 1.25 & -0.19 \\
\hline 36 & $\begin{array}{l}\text { Hot rolled } 62 \% \text { at } \\
1000^{\circ} \mathrm{C} \\
\text { Annealed } 800^{\circ} \mathrm{C}\end{array}$ & 60 & 860 & - & - & 0.90 & 1.22 & 1.50 & 1.21 & -0.02 \\
\hline 37 & $\begin{array}{l}\text { Hot rolled } 62 \% \text { at } \\
1000^{\circ} \mathrm{C} \\
\text { Annealed } 800^{\circ} \mathrm{C}\end{array}$ & 80 & 860 & - & - & 0.57 & 0.77 & 1.15 & 0.80 & +0.09 \\
\hline 38 & Hot cross rolled & & & & & & & & & \\
\hline \multirow{2}{*}{39} & $\begin{array}{l}50 \% \text { at } 1050^{\circ} \mathrm{C} \\
\text { Hot cross rolled }\end{array}$ & 58 & 860 & - & - & 0.44 & 1.34 & 0.74 & 0.97 & -0.75 \\
\hline & $50 \%$ at $1050^{\circ} \mathrm{C}$ & 58 & 820 & 65 & 860 & 1.35 & 2.16 & 2.00 & 1.92 & -0.49 \\
\hline
\end{tabular}

a $2 \mathrm{~h}$. $\quad{ }^{\mathrm{c}}$ Heating rate in range $500-700^{\circ} \mathrm{C}=0.5^{\circ} \mathrm{C} / \mathrm{min}$.

b $3 \mathrm{~h}$. $\quad{ }^{\mathrm{d}} \mathrm{Hold}$ at $750^{\circ} \mathrm{C}$ during cooling omitted. 
TABLE III

Processing history and $R$ values of 410 type steel

\begin{tabular}{|c|c|c|c|c|c|c|c|c|c|c|}
\hline $\begin{array}{l}\text { Treatment } \\
\text { number }\end{array}$ & $\begin{array}{l}\text { Treatment prior } \\
\text { to cold rolling }\end{array}$ & $\begin{array}{c}\text { First } \\
\text { cold } \\
\text { reduction } \\
(\%)\end{array}$ & $\begin{array}{c}\text { Inter- } \\
\text { annealing } \\
\text { temperature } \\
\left({ }^{\circ} \mathrm{C}\right)\end{array}$ & $\begin{array}{c}\text { Second } \\
\text { cold } \\
\text { reduction } \\
(\%)\end{array}$ & $\begin{array}{c}\text { Final } \\
\text { annealing } \\
\text { temperature } \\
\left({ }^{\circ} \mathrm{C}\right)\end{array}$ & $R_{0}$ & $R_{45}$ & $R_{90}$ & $\tilde{R}$ & $\Delta R$ \\
\hline 40 & - & 58 & 820 & 70 & 820 & 1.05 & 1.13 & 1.35 & 1.17 & +0.07 \\
\hline 41 & - & 58 & 820 & 70 & $820^{* \prime}$ & 0.90 & 1.08 & 1.14 & 1.05 & -0.06 \\
\hline 42 & - & 58 & 820 & 70 & 900 & 1.03 & 1.05 & 1.33 & 1.15 & +0.13 \\
\hline 43 & - & - & - & - & - & & & & & \\
\hline \multirow[t]{2}{*}{44} & $\begin{array}{l}\text { Hot rolled } 62 \% \text { at } \\
850^{\circ} \mathrm{C}\end{array}$ & 58 & חרים & 65 & 060 & 0 & & & & \\
\hline & Annealed $800^{\circ} \mathrm{C}$ & 38 & 820 & 03 & 860 & 0.90 & & & & \\
\hline \multirow[t]{2}{*}{45} & Hot rolled $62 \%$ at & & & & & & & & & \\
\hline & $\begin{array}{c}850^{\circ} \mathrm{C} \\
\text { Annealed } 800^{\circ} \mathrm{C}\end{array}$ & 65 & 860 & - & - & 0.78 & & & & \\
\hline 46 & Hot cross rolled & & & & & & & & & \\
\hline \multirow{2}{*}{47} & $50 \%$ at $950^{\circ} \mathrm{C}$ & 58 & 860 & - & - & 0.58 & 1.21 & 0.66 & 0.92 & -0.59 \\
\hline & $50 \%$ at $950^{\circ} \mathrm{C}$ & 58 & 820 & 65 & 860 & 1.12 & 1.43 & 1.48 & 1.37 & -0.13 \\
\hline
\end{tabular}

${ }^{2}$ Heating rate in range $500-700^{\circ} \mathrm{C}=0.5^{\circ} \mathrm{C} / \mathrm{min}$.

with Figure 1a reveals a difference in the starting texture of the two materials, and differences are maintained after the final cold rolling reduction (Figures $9 \mathrm{~b}$ and 1c) and after final annealing (Figures 9c and 7). In particular, the pole figure of cold rolled 410 steel gives no definite indication of the presence of $\{554\}\langle 225\rangle$, a component which appears to be present in the cold rolled 405 steel. In the final annealed condition, the 410 steel pole figure is reminiscent of $\{200\}$ pole figures obtained from deep drawing quality plain low-carbon steels, with a pseudo-four-fold symmetry associated with the near- $\{111\}$ component. In contrast the 405 steel shows a well-defined $\{554\}\langle 225\rangle$ texture, the pole figure exhibiting six-fold symmetry.

The remaining treatments (30-39 and 43-47) were designed to explore the difference in behaviour of the two steels more fully. These involved either heat treatment of the hot rolled material or further hot rolling of the hot band material, prior to cold rolling and annealing.

The hot band 405 material was heated to $1000^{\circ} \mathrm{C}$ and air cooled (treatment 31 ) prior to a double cold reduction (treatment 32 ). The $\bar{R}$ value following this latter treatment was still high $(\bar{R}=1.76)$ and the pole figure for this condition is shown in Figure 11. The aim of this experiment was to modify the starting texture of the 405 , and the pole figure corresponding to treatment 31 , Figure 10, indicates that some change of texture has taken place, compared with Figure 1a. However such changes as did occur were not sufficient to reduce the level of $\bar{R}$ to that of the 410 material. The development of anisotropy was followed from this initial condition by measuring $R$ values after a single cold reduction corresponding to the first reduction in the double reduction treatment. The very low $\bar{R}$ value at this stage $(\bar{R}=0.81$, treatment 33 ) is an indication that there is a progressive development of high $\bar{R}$ values in the two-stage reduction process. Further indications that the $\bar{R}$ value attained at the intermediate stage is low are given by comparing treatments 38 and 39 , and also treatments 46 and 47.

The influence of hot rolling temperature is shown by reference to treatments 34-37. From these limited results it appears that the lower hot rolling temperature gives higher $\bar{R}$ values.

Finally, further hot rolling of the hot band was followed by single and double cold reductions. In view of the slightly lower $\alpha \rightarrow(\alpha+\gamma)$ transformation temperature of the 410 steel compared with the 405 steel (determined from hardness measurements of air cooled samples), the hot rolling temperature used for the 410 steel was somewhat lower than that used for the 405 . The $\bar{R}$ achieved by the double reduced 405 steel (treatment 39 ) was comparable with the highest values obtained for this material. The corresponding treatment for the 410 steel (treatment 47 ) produced the highest value of $\bar{R}$ obtained in the limited range of experiments carried out on this material. The pole figure (Figure 12) indicates 

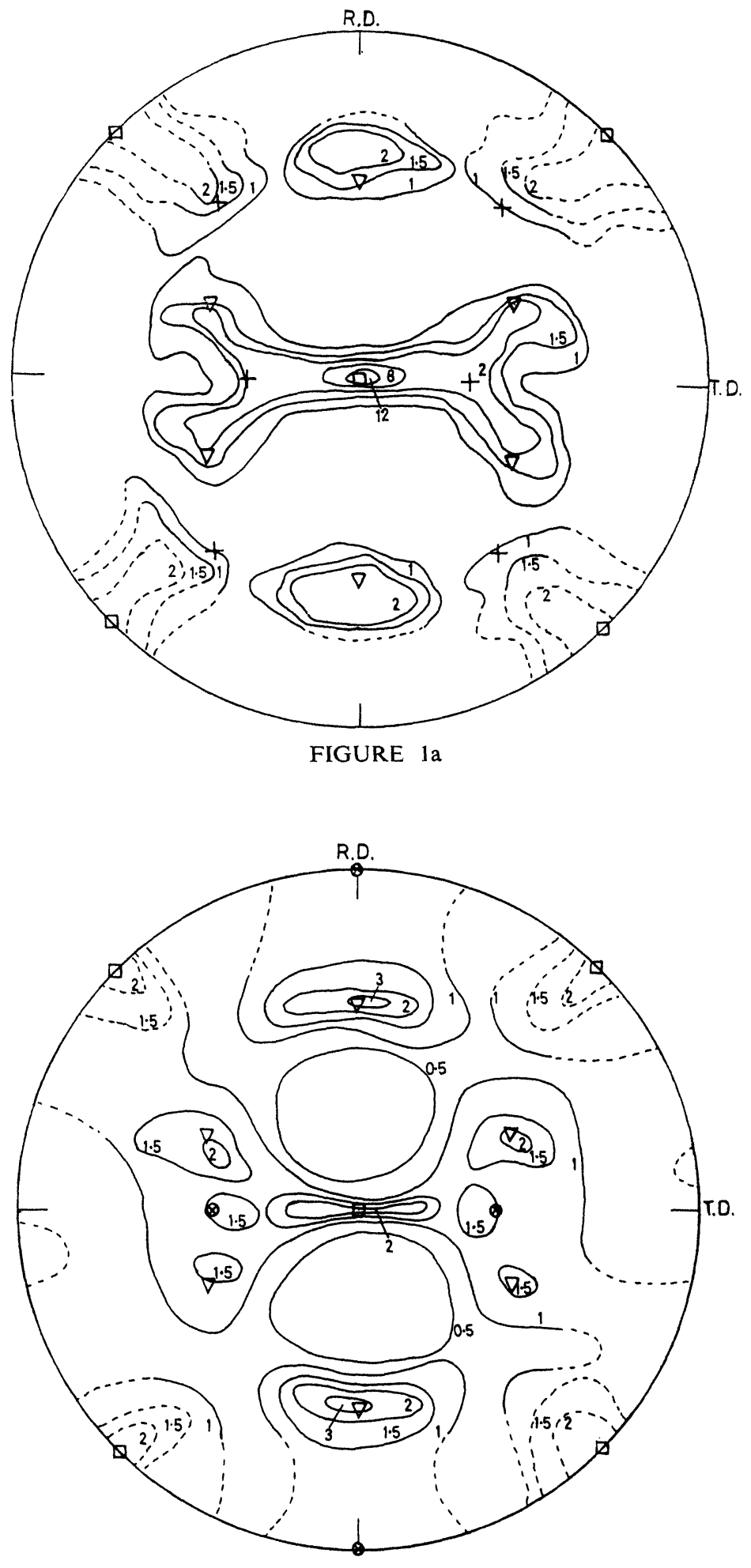

FIGURE $1 \mathrm{~b}$ 


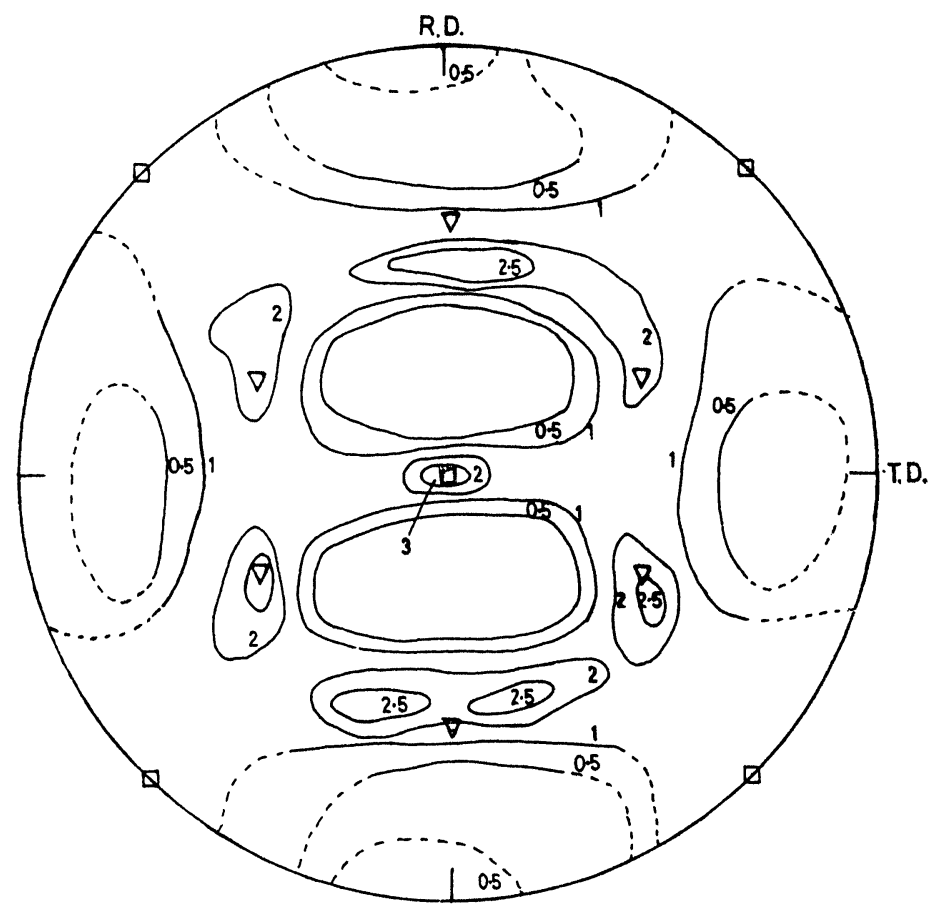

FIGURE 1c

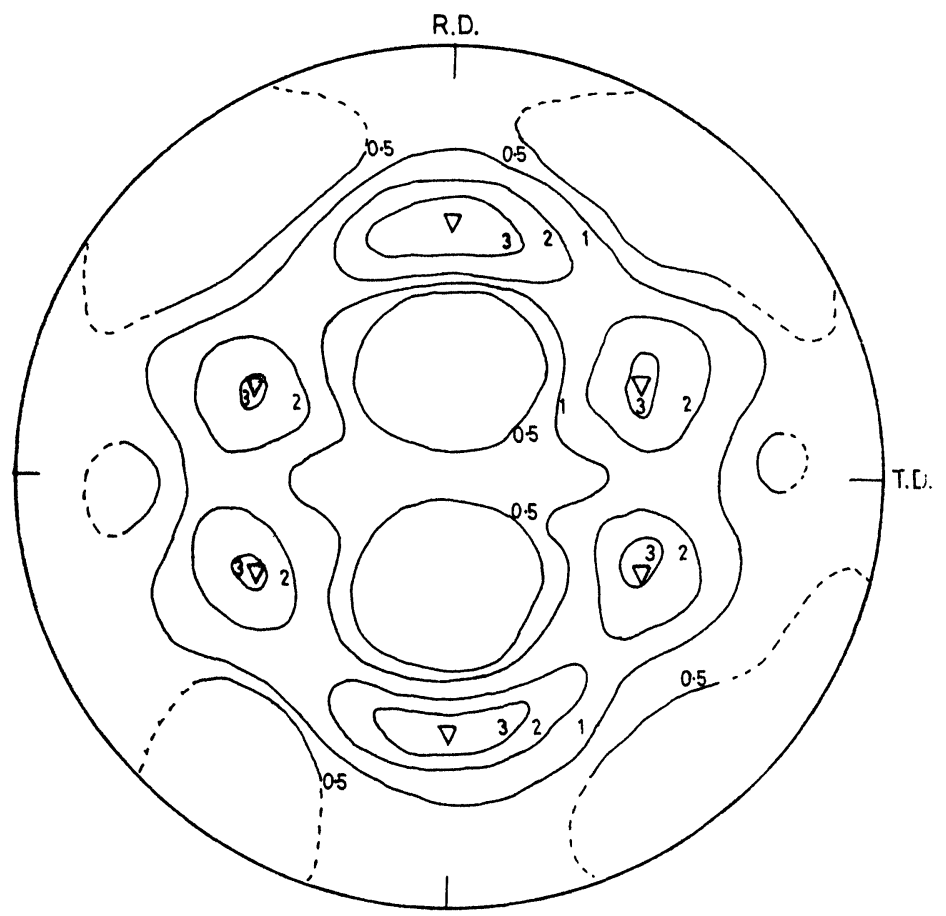

FIGURE 1d

FIGURE $1\{200\}$ pole figures of 405 type stainless steel at various stages in the rolling process (treatment 3 ). (a) Asreceived material (hot-rolled and softened)-centre section. (b) After a first cold reduction of $58 \%$ and an intermediate anneal at $750^{\circ} \mathrm{C}$ for $1 \mathrm{~h}$. (c) After a second cold reduction of $70 \%$. (d) After a final anneal at $750^{\circ} \mathrm{C}$ for $1 \mathrm{~h} . \quad \square\{100\}$ $\langle 011\rangle,+\{112\}\langle 011\rangle, \nabla\{554\}\langle 225\rangle, \otimes \quad\{110\}\langle 001\rangle$. Numbers on contour lines refer to multiples of random intensity. 


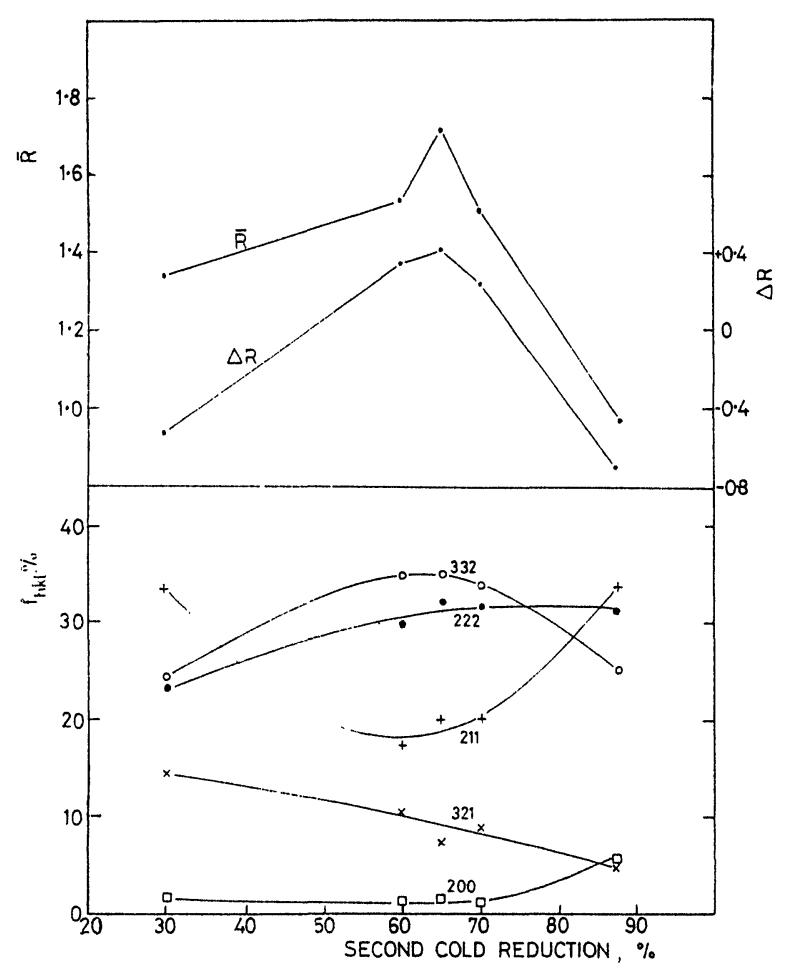

FIGURE 2 Effects of variation in the second cold reduction on $R$ values and texture parameters. 405 steel with intermediate and final anneals at $750^{\circ} \mathrm{C}$.

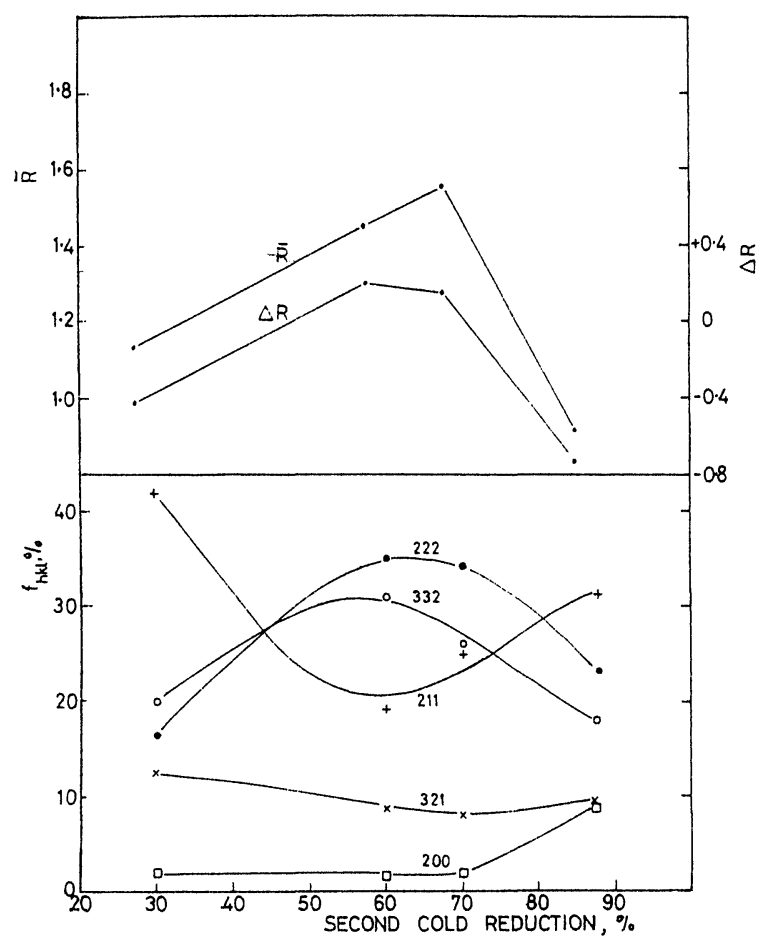

FIGURE 3 Effects of variation in the second cold reduction on $R$ values and texture parameters. 405 steel with intermediate anneal at $750^{\circ} \mathrm{C}$ and final anneal at $1050^{\circ} \mathrm{C}$.

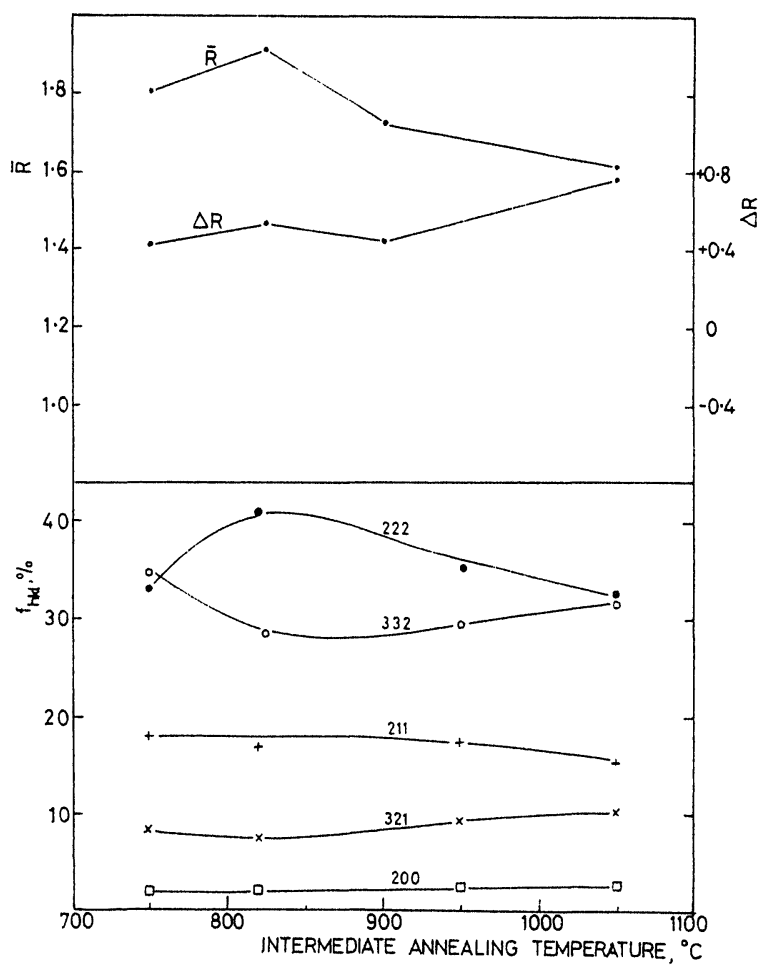

FIGURE 4 Effects of variation in the intermediate annealing temperature on $R$ values and texture parameters. 405 steel with a second cold reduction of $70 \%$ and a final anneal at $750^{\circ} \mathrm{C}$.

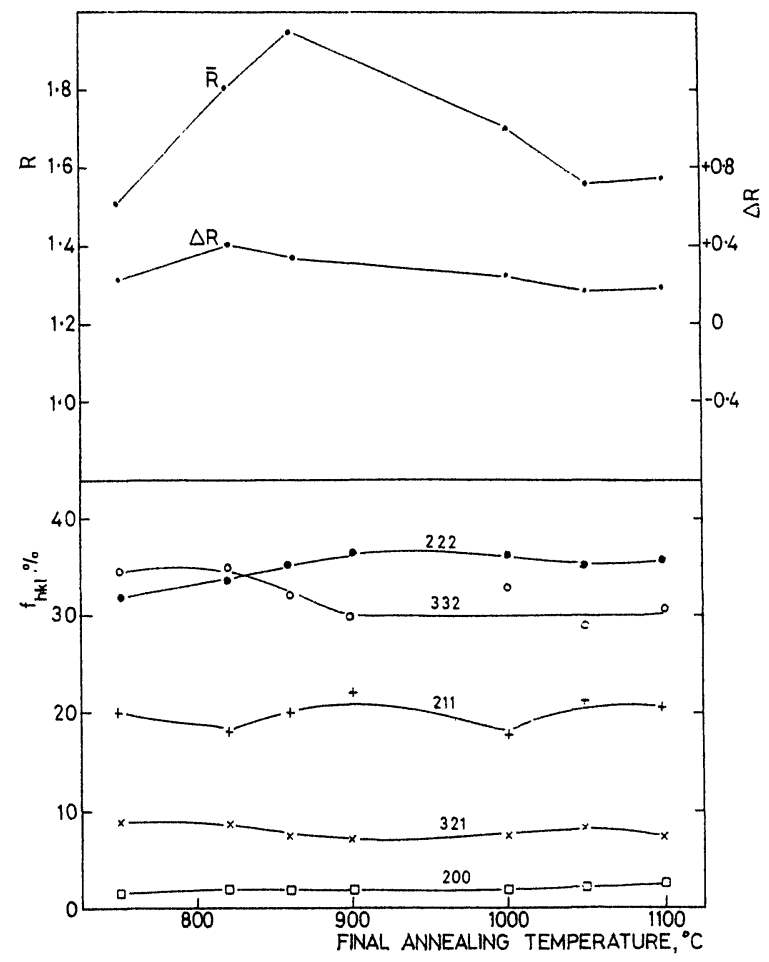

FIGURE 5 Effects of variation in the final annealing temperature on $R$ values and texture parameters. 405 steel with an intermediate anneal at $750^{\circ} \mathrm{C}$ and a second cold reduction of $70 \%$. 


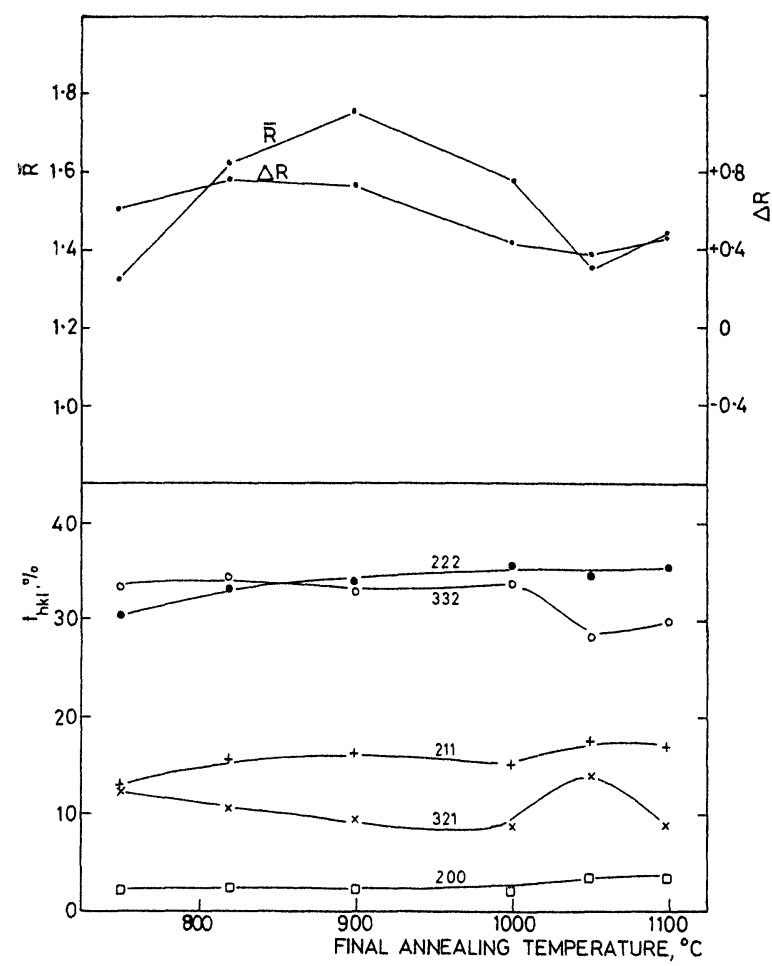

FIGURE 6 Effects of variation in the final annealing temperature on $R$ values and texture parameters. 405 steel with an intermediate anneal at $1050^{\circ} \mathrm{C}$ and a second cold reduction of $70 \%$.

that the 410 steel has developed a strong $\{554\}\langle 225\rangle$ texture in this condition, but the relatively high concentration of $\{100\}$ poles at the centre of the pole figure counteracts the beneficial effect of the near- $\{111\}$ orientations and accounts for the only moderate $\bar{R}$ value of 1.37 . Nevertheless, there is a clear indication that the behaviour of the 410 steel could be similar to that of the 405 steel if the hot rolling conditions for the two materials were carefully selected.

The deep drawing tests carried out on the 405 steel (Figure 13) conform to the well-established linear relationship between the limiting drawing ratio and $\bar{R}$ over the range of $\bar{R}$ between 0.9 and 2.0.

\section{DISCUSSION}

Before embarking on a detailed discussion of the recrystallisation textures observed, it will be convenient to summarise some of the ideal orientations used, and in particular those used to describe near$\{111\}\langle 112\rangle$ orientations (Figure 14). The descrip- tion $\{554\}\langle 225\rangle$ is an empirical description which appears to fit the peak positions on $\{200\}$ pole figures well in certain instances. The orientation $\{332\}\langle 113\rangle$ is obtained by further tilt of $\{554\}\langle 225\rangle$ about the transverse direction, and in between these two orientations lies $\{11,11,8\}\langle 4,4,11\rangle$, a theoretically stable orientation during rolling of b.c.c. metals. ${ }^{12}$ The $\{111\}$ and $\{332\}$ components are monitored by the inverse pole figure method used.

In commercial annealed low carbon steels, $\{200\}$ pole figures tend to show four-fold symmetry (similar to Figure 9c), and from such a pole figure alone it is not evident which directions are aligned in the rolling direction. More detailed analysis of the recrystallisation texture of $70 \%$ cold rolled and annealed A1-killed steel ${ }^{13}$ reveals that $\{111\}\langle 110\rangle$ is about $50 \%$ in excess of near- $\{111\}\langle 112\rangle$. Heyer et al. ${ }^{1}$ showed that, in rimmed steel, $\{111\}\langle 112\rangle$ increased at the expense of $\{111\}\langle 110\rangle$ with increasing cold reduction, the peaks associated with $\{111\}\langle 112\rangle$ becoming recognisable after $85-90 \%$ cold reduction. A similar trend was reported more recently by Ormay and Richards in rimmed steel ${ }^{3}$ and by Evans et al. in iron and some iron alloys. ${ }^{14}$

In low carbon steels, the development of a strong $\{554\}\langle 225\rangle$ texture is generally accompanied by the simultaneous development of a texture with $\{100\}$ planes nearly parallel to the surface, and consequently the $\bar{R}$ values are less than those obtainable after smaller cold reductions. In the $\mathrm{Fe}-0.5 \mathrm{Ti}$ alloy examined by Evans et al. ${ }^{14}$, a strong $\{554\}\langle 225\rangle$ was developed with a minor $\{100\}\langle 210\rangle$ component and a high $\bar{R}$ was obtained after $92 \%$ cold reduction. The $\mathrm{Fe}-0.5 \mathrm{Ti}$ alloy was grouped with other alloys which showed a continuously increasing $\bar{R}$ with cold reduction up to over $90 \%$ cold reduction.

An interesting feature of the textures in the ferritic stainless steels is that the strong $\{554\}\langle 225\rangle$ with a small proportion of $\{100\}$ component is produced after only moderate second cold reductions $(65-70 \%)$. It is believed that the reason for this lies in the progressive development of the $\{554\}\langle 225\rangle$ component throughout the processing of the sheet. It appears to be present in the hot rolled and softened 405 (Figure 1a) and also in the material after the intermediate anneal (Figure 1b), although in this case it is associated with a strong $\{100\}\langle 110\rangle$ component which is the cause of the low $\bar{R}$ values obtained at this stage.

The texture after the second cold reduction, 
TABLE IV

\begin{tabular}{|c|c|c|c|c|c|c|c|c|c|}
\hline \multirow{2}{*}{ Material } & \multirow{2}{*}{$\begin{array}{c}\text { Treatment } \\
\text { number }\end{array}$} & \multicolumn{8}{|c|}{$f_{h k l}(\%)$} \\
\hline & & 110 & 200 & 211 & 310 & 222 & 321 & 420 & 332 \\
\hline 410 & 40 & 1.7 & 2.2 & 20.0 & 6.0 & 20.0 & 15.2 & 6.7 & 27.5 \\
\hline 405 & 25 & 0.1 & 2.0 & 17.0 & 2.0 & 41.6 & 7.5 & 0.9 & 28.8 \\
\hline 410 & 42 & 2.5 & 3.0 & 21.5 & 7.0 & 20.2 & 15.7 & 5.7 & 23.7 \\
\hline 405 & 26 & 0.6 & 2.0 & 18.5 & 2.2 & 31.5 & 8.7 & 0.5 & 36.0 \\
\hline
\end{tabular}

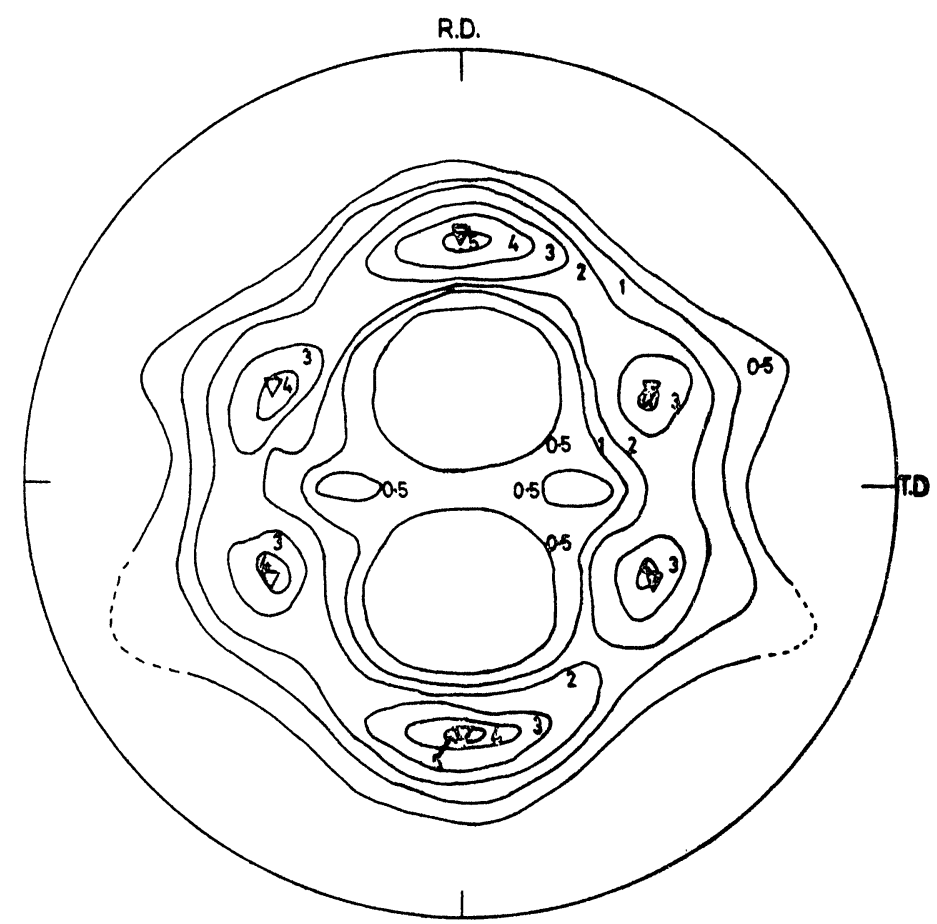

FIGURE $7\{200\}$ pole figure of 405 stainless steel following an intermediate anneal at $750^{\circ} \mathrm{C}$, a second cold reduction of $70 \%$ and a final anneal at $900^{\circ} \mathrm{C} 1 \mathrm{~h}$. (treatment 16$) . \quad \nabla\{554\}\langle 225\rangle$.

Figure 1c, is not typical of cold rolled b.c.c. metals as it contains identifiable peaks associated with $\{554\}\langle 225\rangle$ and the final anneal (Figure 1d) enhances this component with a marked reduction in the $\{100\}$ texture component.

It was shown experimentally by $\mathrm{Hu}$ and $\mathrm{Cline}^{15}$ that a single crystal of $\mathrm{Fe}-2 \mathrm{Al}$ with initial orientation close to (111)[11 2$]$ essentially retained its initial orientation after cold rolling reductions up to $70 \%$, although slight displacements of the peak intensity positions on the pole figures towards (554) $[\overline{2} \overline{2} 5]$ were shown. Based on a Taylor model of crystal deformation, Dillamore et al. ${ }^{12}$ predicted that $(11,11,8)[\overline{4}, \overline{4}, 11]$ (about $2^{\circ}$ from $(554)[\overline{2} \overline{2} 5]$ ) would be a stable orientation during rolling. There is therefore experimental and theoretical evidence that orientations close to $\{554\}\langle 225\rangle$ will persist during cold rolling. Furthermore, subgrains in this orientation have a high nucleation probability ${ }^{16}$ and will recrystallise at an early stage in the annealing process. Having gained an early size advantage, they will continue to grow during the annealing cycle.

With very heavy cold reductions, it is likely that differences in nucleation rate between the various orientations will play a less important role, and 


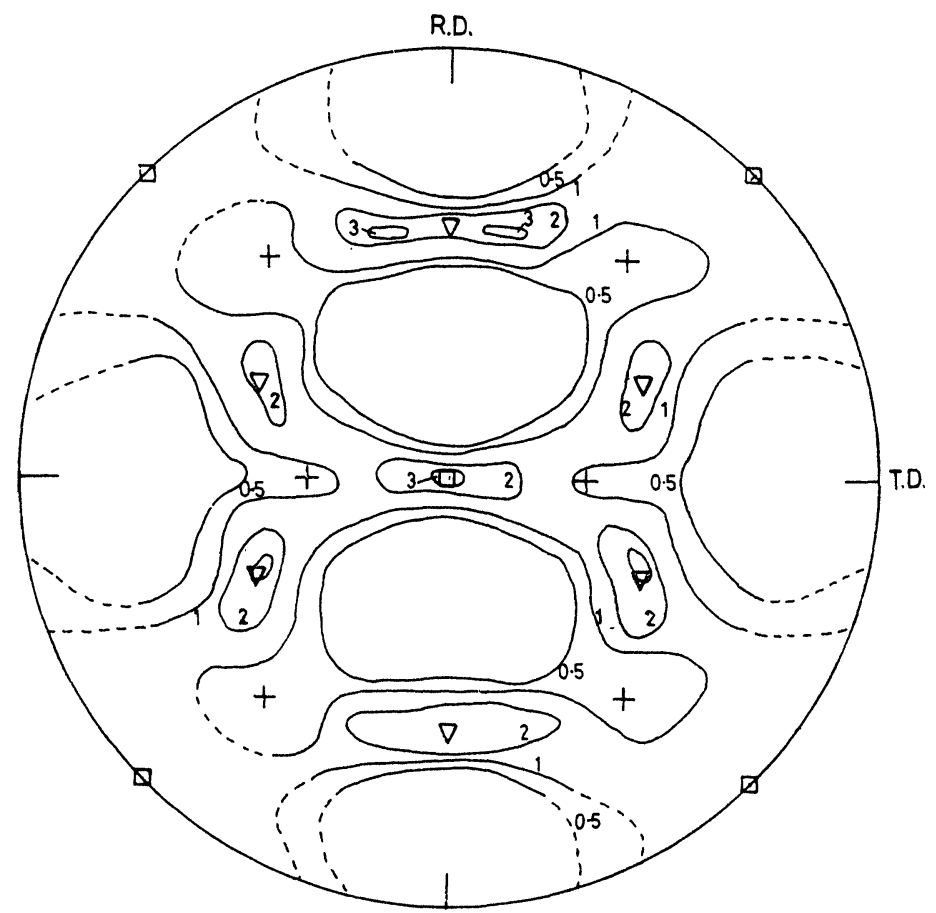

FIGURE $8 \quad\left\{200\right.$; pole figure of 405 sieel after a cold reduction of $87.5 \%$ and a final anneal at $750^{\circ} \mathrm{C}$ (treatment 1 ). $\square\{100\}\langle 011\rangle,+\{112\}\langle 011\rangle, \nabla\{554\}\langle 225\rangle$. Numbers on contour lines refer to multiples of random intensity.

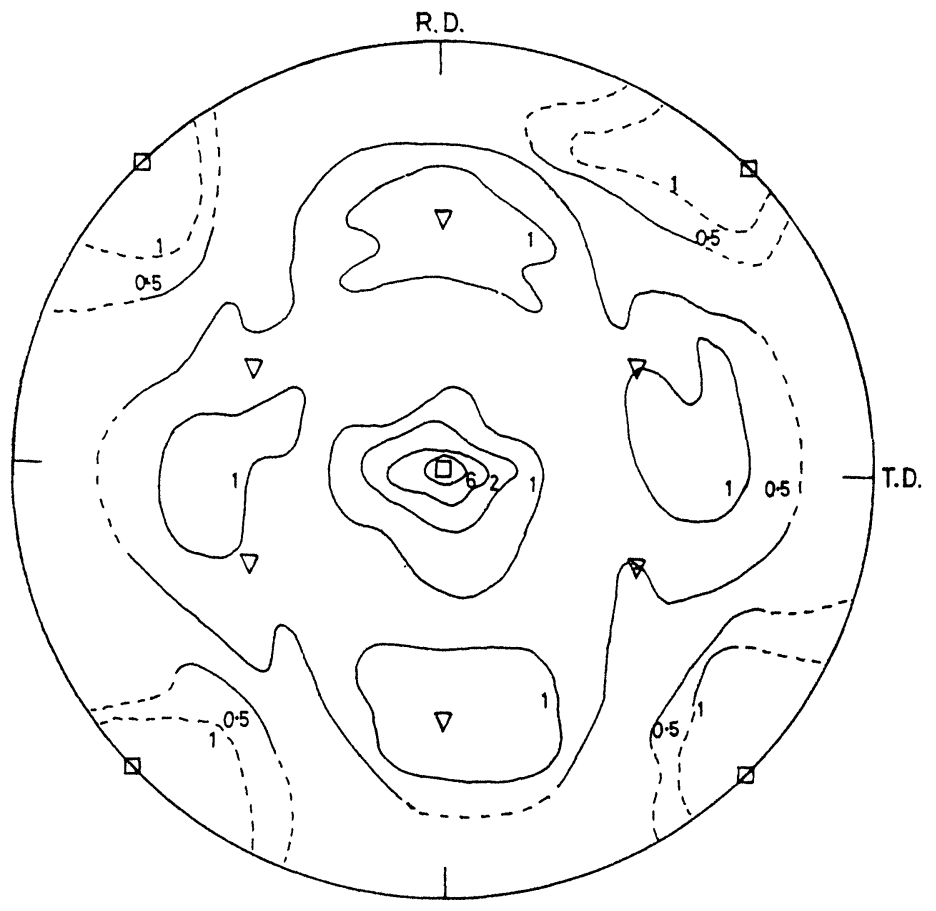

FIGURE 9a 


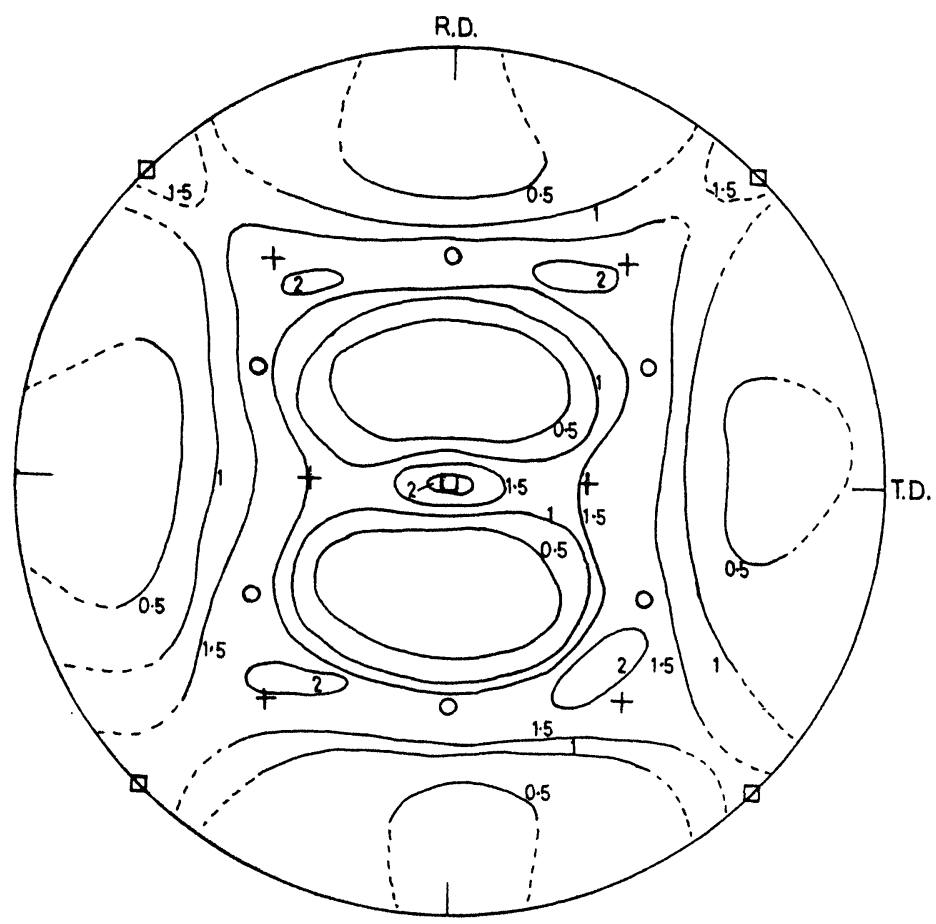

FIGURE $9 \mathrm{~b}$

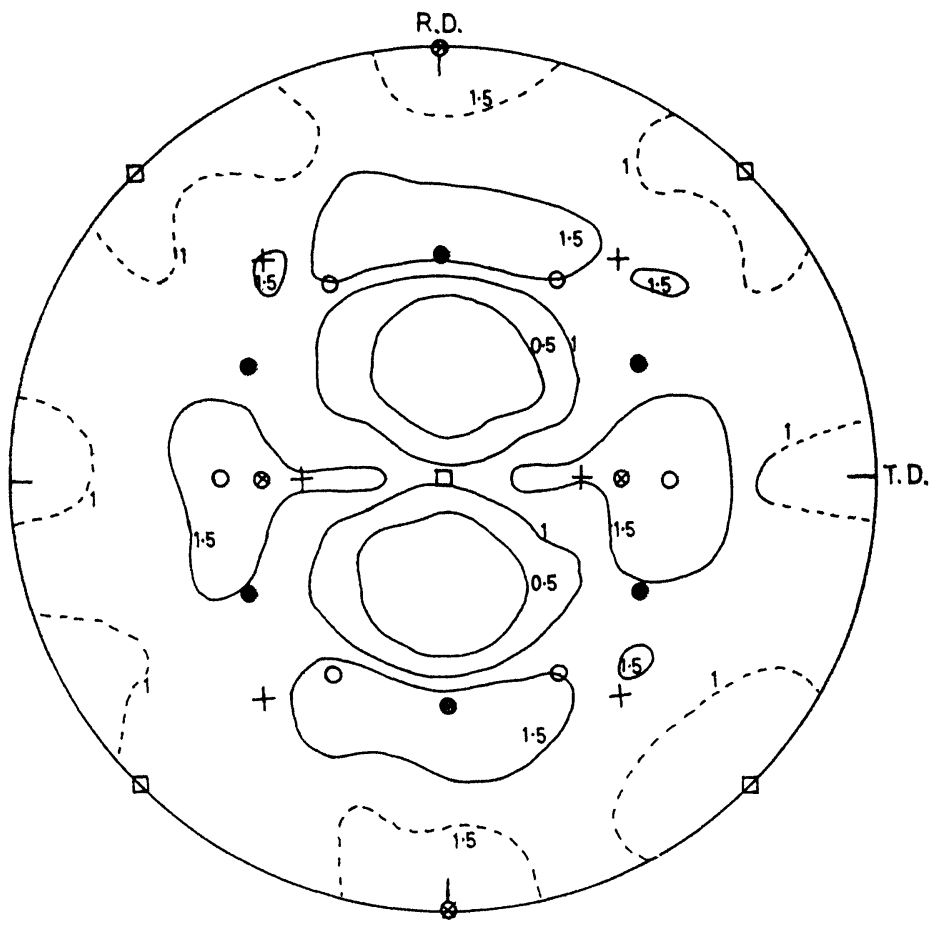

FIGURE 9c

FIGURE $9\{200\}$ pole figures of 410 type stainless steel at various stages in the rolling process (treatment 42 ).

(a) As-received material (hot rolled and softened) -centre section. (b) After a second cold reduction of $70 \%$.

(c) After a final anneal at $900^{\circ} \mathrm{C} 1 \mathrm{~h} . \quad \square\{100\}\langle 011\rangle,+\{112\}\langle 011\rangle, \quad \nabla\{554\}\langle 225\rangle, \quad \bigcirc\{111\}\langle 011\rangle$,

$\{111\}\langle 112\rangle, \otimes\{110\}\langle 001\rangle$. Numbers on contour lines refer to multiples of random intensity. 


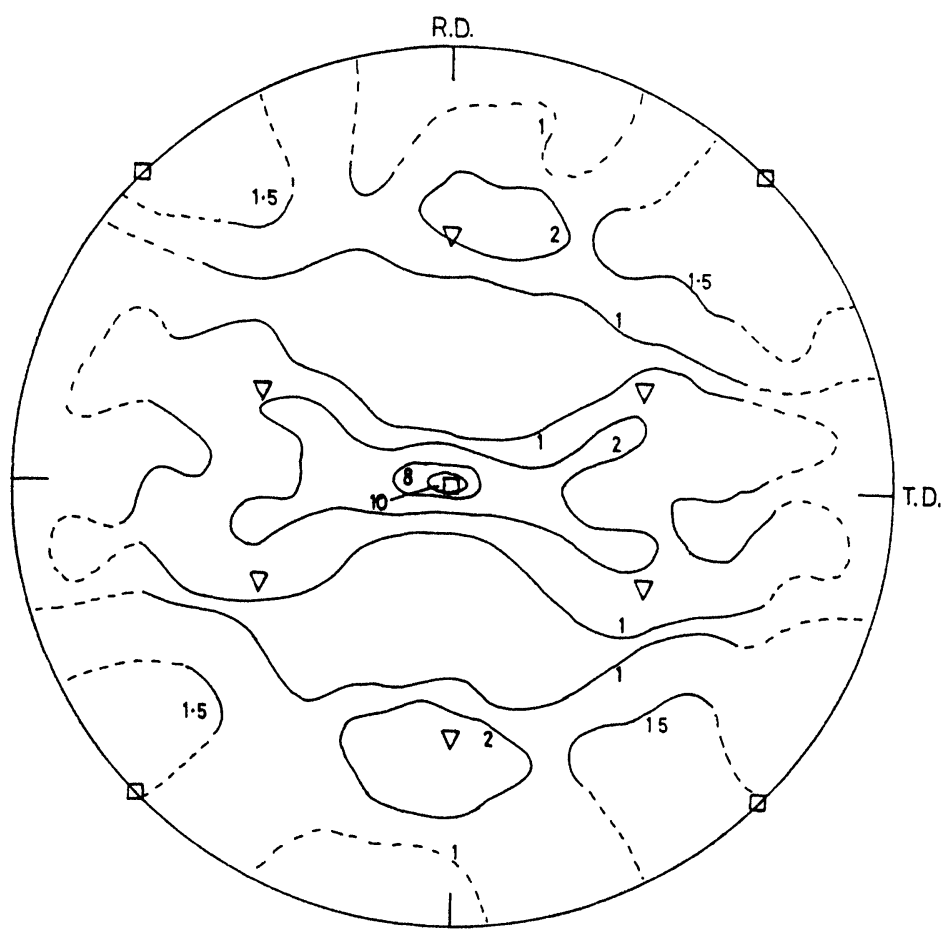

FIGURE $10\{200\}$ pole figure of 405 steel-as-received material after a further heat treatment at $1000^{\circ} \mathrm{C}$ followed by air cooling. $\square\{100\}\langle 011\rangle, \Delta\{554\}\langle 225\rangle$.

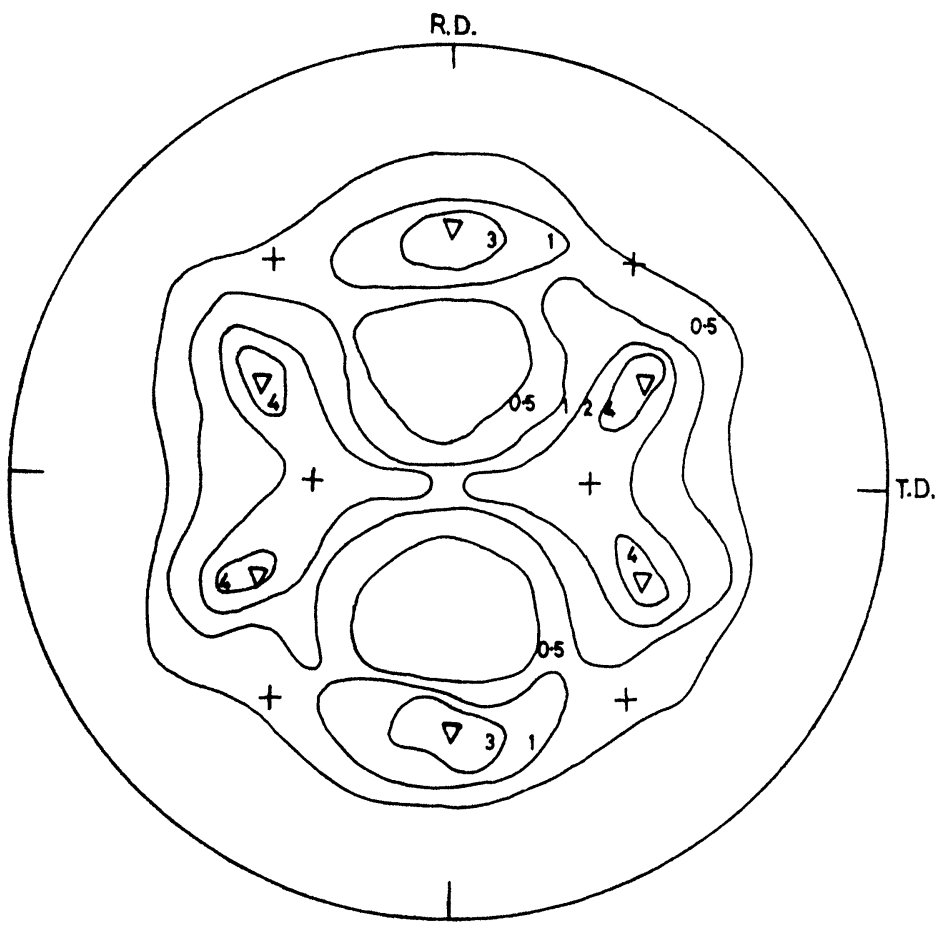

FIGURE $11\{200\}$ pole figure of 405 steel. The as-received material was heat treated at $1000^{\circ} \mathrm{C}$ (as in Figure 10) and then given a first cold reduction of $58 \%$, an intermediate anneal at $820{ }^{\circ} \mathrm{C}$, a second cold reduction of $70 \%$ and a final anneal at $860^{\circ} \mathrm{C}$ (treatment 32). $\quad \nabla\{554\}\langle 225\rangle, \quad+\{112\}\langle 011\rangle . \quad$ Numbers on contour lines refer to multiples of random intensity. 


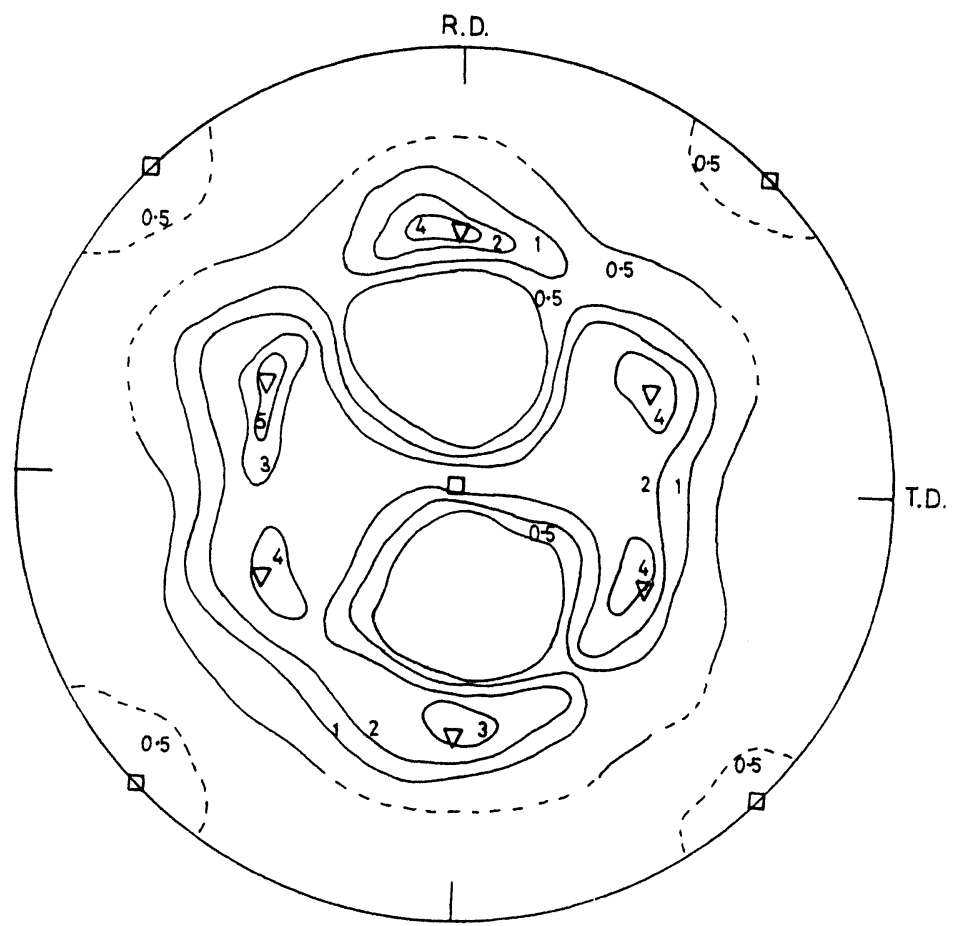

FIGURE $12\{200\}$ pole figure of 410 steel (treatment 47 ). $\square\{100\}\langle 011 \%, \quad \nabla\{554\}\langle 225\rangle$. Numbers on contour lines refer to multiples of random intensity.

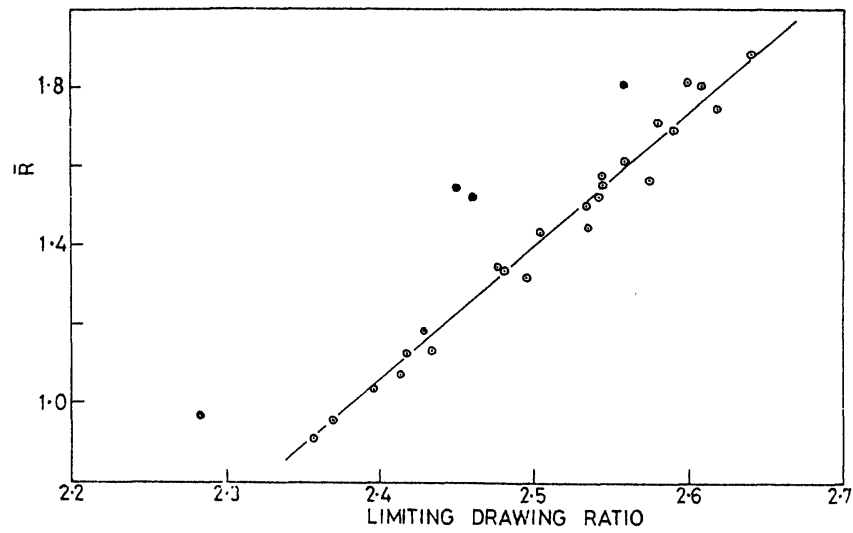

FIGURE 13 Variation of limiting drawing ratio with $R$. Open circles-single blank draw-fracture test. Full circles-Swift test.

under these conditions $\{111\}$ and near- $\{100\}$ components form the major part of the textural spread.

The favourable normal anisotropy developed in 405 steel is accompanied by a degree of planar anisotropy which is lower than that usually obtained in low carbon steels. The planar anisotropy, measured by $\Delta R$, is strongly correlated with the amount of material with $\{211\}$ parallel to the surface (Figure 15). Planar anisotropy has previously been associated with the ratio $f_{211} / f_{110},{ }^{17}$ but in the ferritic steels, with the single exception of treatment $33\left(f_{110}=9.9 \%\right)$ the values of $f_{110}$ were very low. This offered an opportunity to derive a relationship between $\Delta R$ and $f_{211}$ in the absence of significant variations in $f_{110}$. The correlation between $\Delta R$ and $f_{211}$ is consistent with the theor- 
etical prediction of Vieth and Whiteley ${ }^{18}$ assuming that the textural component present is $\{211\}\langle 110\rangle$.

The causes of the differences in behaviour between the 405 steel and the 410 steel have not been identified unequivocally, but available evidence suggests that differences in their textures evolved progressively, from the hot rolling stage onwards.

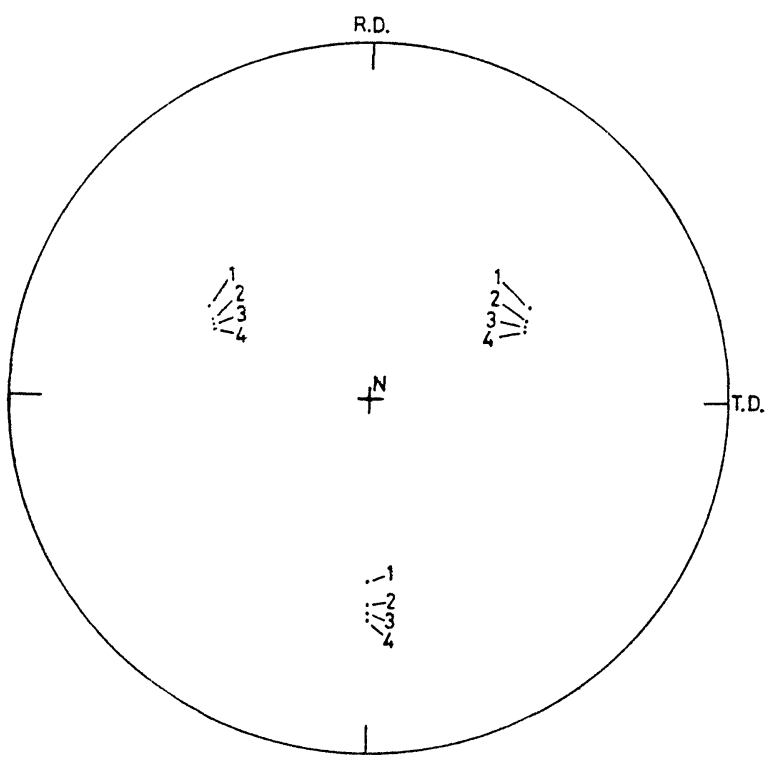

FIGURE 14 Ideal orientations close to $\{111\}\langle 211\rangle .1$. (111) $[211] \quad 2$. (455) $[522] \quad 3$. $(8,11,11)[11,4,4] \quad 4$. (233) [311].

Thus practically the whole of the processing history appears to be potentially significant. One possibility considered was that the recrystallisation textures were influenced by differences in the precipitation or the distribution of carbides and/or nitrides in the two steels. In this context, two observations made in the present work appear to preclude any close analogy between the behaviour of the 405 steel and that of a low carbon steel stabilised with aluminium. Firstly, precipitation from supersaturated solid solution would occur on reheating at the intermediate annealing stage and it is unlikely that further precipitation of this kind would be available to influence the final recrystallisation texture in the chromium steel. Secondly, high $R$ values were obtained in the 405 steel even after final annealing by immersion in a salt bath. Such rapid heating is known to destroy the beneficial effect of AIN precipitation in stabilised steels.
More generally, however, it is likely that the dispersions of second phase particles (mainly carbides) that were present in the chromium steels did influence recrystallisation and grain growth. An important difference between high chromium and plain carbon steels is that, in the former, carbide precipitates are relatively resistant to coarsening at the recrystallisation temperature. The results for treatments 14 and 27 appear to be consistent with the idea that a fine dispersion of carbide particles tends to promote textural improvements during grain growth, but the effect was not large. Treatment 27 , which led to the development of relatively coarse carbides as a result of intermediate annealing at $950^{\circ} \mathrm{C}$, gave an $\bar{R}$ value only about 0.1 lower than that obtained with treatment 14 (intermediate anneal at $750^{\circ} \mathrm{C}$ ). Since no large differences in precipitate distribution were observed in the two steels after equivalent intermediate and final annealing treatments, it was concluded that differences in second phase particle distributions that were present during final recrystallisation are unlikely to have been a principal source of differences in textural behaviour. Rather, the textural evidence suggests that the differences in behaviour of the two steels depended on conditions that were established at an early stage of processing.

In the initial hot rolled and softened condition the presence of a near- $\{111\}\langle 112\rangle$ component could be recognised in the texture of the 405 steel but not in that of the 410 steel. Also the cold rolled texture of the 410 steel (Figure $9 \mathrm{~b}$ ) is typical of previously reported b.c.c. rolling textures, with a main component $\{100\}\langle 110\rangle$, spread about the rolling direction and peaks close to $\{112\}\langle 110\rangle$. The absence of identifiable near- $\{111\}\langle 112\rangle$ peaks throughout the processing of the 410 steel, and even in the final annealed condition, is attributed to the hot rolling and softening procedure. It was found possible by carrying out further hot rolling to generate a distinct $\{554\}\langle 225\rangle$ texture in the 410 steel in the final cold rolled and annealed condition (Figure 12). By control of the hot rolling procedure, it would almost certainly be possible to produce the 410 steel with anisotropic characteristics similar to the 405 steel.

Comparing the present work on $13 \mathrm{Cr}$ ferritic steel with that of Gokyu and Suzuki ${ }^{9}$ on $18 \mathrm{Cr}$ ferritic steel, some similarities in the behaviour of the two types of material are apparent. The anisotropic characteristics of the $18 \mathrm{Cr}$ steel are better after a double cold reduction than after a single reduction, and a large effect of hot rolling tem- 


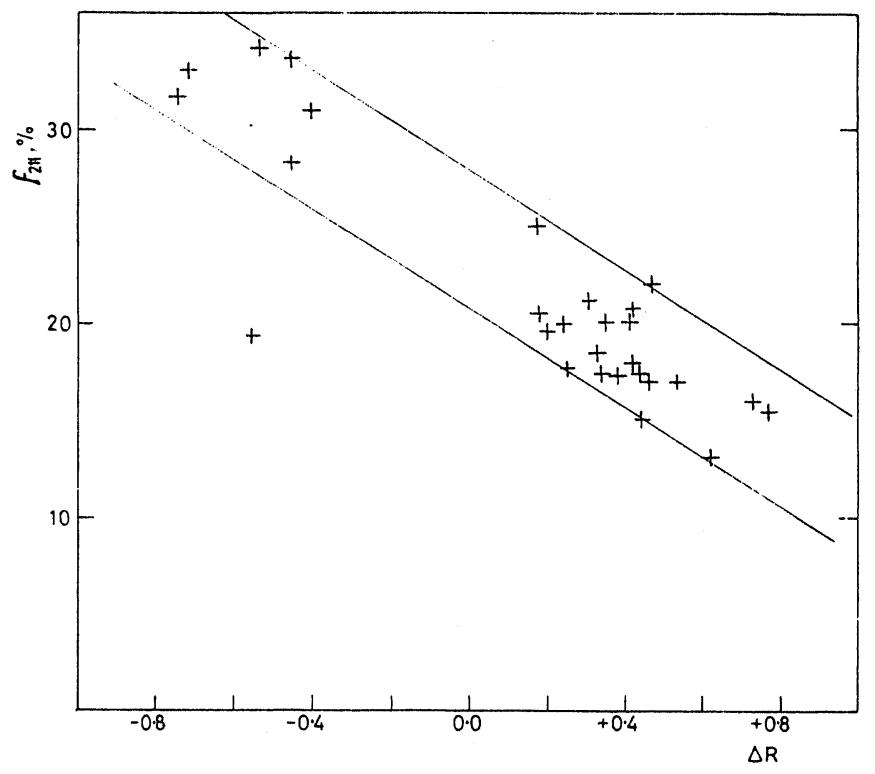

FIGURE 15 Relationship between volume fraction of material with $\{211\}$ parallel to sheet surface, $f_{211}$, and $\Delta R$.

perature was noted. Gokyu and Suzuki explored the rolling temperature range $700-1000^{\circ} \mathrm{C}$ and obtained their highest $\bar{R}$ values after hot rolling at $700^{\circ} \mathrm{C}$. This may be too low to exploit from a practical production viewpoint. They also noted an improvement in $\bar{R}$ by water-quenching after hot rolling instead of air cooling. The levels of $\bar{R}$ attained in the present work are somewhat higher than those obtained by Gokyu and Suzuki, even after their hot rolling at $700^{\circ} \mathrm{C}$, and if the hot rolling temperature is restricted to above $900^{\circ} \mathrm{C}$, the difference in levels of $\bar{R}$ is considerable.

\section{SUMMARY}

1) In 405 type steel, anisotropic characteristics very favourable for deep drawing have been produced following a double cold reduction with two reductions of $60-70 \%$, and a final anneal in the temperature range $820-900^{\circ} \mathrm{C}$.

2) The favourable anisotropy develops progressively during fabrication and is associated with the presence of a strong $\{554\}\langle 225\rangle$ textural component, together with the absence of orientations with $\{100\}$ planes parallel to the sheet surface.

3) It is unlikely that precipitation plays a major role in the development of the final recrystallisation texture.
4) The high degree of normal anisotropy is associated with a degree of planar anisotropy which is less than that usually encountered in E.D.D. quality killed steels.

5) Differences in planar anisotropy appear to be associated mainly with variations in the textural component $\{211\}\langle 110\rangle$.

6) Differences between 405 steel and 410 steel used in the present work have been attributed to textural differences present in the as-received hot rolled and softened materials.

\section{ACKNOWLEDGEMENTS}

Thanks are due to Professor E. C. Rollason for the provision of laboratory facilities and Firth-Vickers Stainless Steels Ltd. for providing the steels. We also acknowledge the assistance of Mr. C. Bulutgil in part of the experimental work dealing with the 410 steel.

\section{REFERENCES}

1. R. H. Heyer, D. E. McCabe and J. A. Elias, Flat Rolled Products III (Interscience, New York, 1962), pp. 29-46.

2. R. L. Whiteley and D. E. Wise, Ref. 1, pp. 47-61.

3. M. K. Ormay and P. N. Richards, TMS-AIME 245, 2081 (1969).

4. J. T. Michalak and R. D. Schoone, TMS-AIME 242, 1149 (1968).

5. D. J. Blickwede, Trans. ASM 61, 653 (1968). 
6. H. Takechi, H. Kato and S. Nagashima, TMS-AIME242, 56 (1968).

7. H-C. Chao, Trans. ASM 60, 37 (1967).

8. H. Takechi, H. Kato, T. Sunami and T. Nakayama, Trans. Japan. Inst. Met. 8, 233 (1967).

9. I. Gokyu and K. Suzuki, Proc. I.D.D.R.G. Meeting, 1968, Turin (Inst. of Sheet Met. Eng.)

10. D. V. Wilson, B. J. Sunter and D. F. Martin, Sheet Metal Ind. 43, 465 (1966).

11. R. M. S. B. Horta, W. T. Roberts and D. V. Wilson, TMS-AIME 245, 2525 (1969).

12. I. L. Dillamore, E. Butler and D. Green, Met. Sci. J. 2, 161 (1968).
13. H-J. Bunge and W. T. Roberts, J. Appl. Cryst. 2, 116 (1969)

14. P. R. V. Evans, J. C. Bitcon and I. F. Hughes, J. Iron Steel Inst. 207, 331 (1969).

15. H. Hu and R. S. Cline, TMS-AIME 224, 784 (1962).

16. I. L. Dillamore, P. L. Morris, C. J. E. Smith and W. B. Hutchinson, to be published.

17. R. M. S. B. Horta, D. V. Wilson and W. T. Roberts, J. Iron Steel Inst. 21042 (1972).

18. R. W. Vieth and R. L. Whiteley, Proc. I.D.D.R.G. Meeting, 1964, London (Inst. of Sheet Met. Eng.) 